\title{
PIERCINGS. ¿MODA O ABERRACIÓN?
}

\author{
PIERCINGS. FASHION OR ABERRANCE?
}

FECHA DE RECIBO: JUNIO 1, 2012

FECHA DE ACEPTACIÓN: JUNIO 29, 2012

\section{NANCY ROSARIO BRIEVA HURTADO}

\begin{abstract}
Tecnóloga en Diseño de Modas y Textil. Profesional en Diseño de Modas y Alta Costura. Psicóloga Social. Docente catedrática del Programa Diseño De Modas y Alta Costura de la Universidad Autónoma Del Caribe
\end{abstract}

\section{RESUMEN:}

Es preciso reconocer que la juventud cada vez va buscando diferentes maneras de identificarse en lo personal y emocional, búsqueda que en ocasiones, los ha llevado a involucrarse en distractores como alcohol, sexo, drogas, y todo tipo de alternativas de escape como lo son, la música y artes en ge-neral. La práctica del piercing se ha convertido en una forma de llamar la atención o pasaporte para ingreso a los grupos de subcultura que conforman los jóvenes de nuestro mundo. Otros son atraídos porque son víctimas de estados depresivos, viven con melancolía por lo que no pudo ser, recuerdos de seres queridos que hoy ya no están, estos entre otras, son los motivos que conducen a los jóvenes y simpatizantes de los piercings a hacerse perforaciones o las llamadas decoraciones corporales con joyas. Esta es una práctica milenaria, que sin duda alguna se ha ido posicionando hasta convertirse en moda, tanto así, que su impacto es cada día más relevante y fuerte entre los adeptos y no adeptos a esta forma de decoración corporal, creando una gran división de criterios en la sociedad.

PALABRAS CLAVE:

Piercings, abertura, moda, accesorio, decoración, perforación, adorno, arte, jóvenes, cultura.

\section{ABSTRACT:}

We need to admit that youth is always looking for different ways to recognize themselves. Frequently, this search has led them to alcohol, sex, drugs, and all other type of escape activities such as music and arts. Piercing practices became a way to attract attention and to get into youth subculture groups. Young people in depressive conditions are attracted too. Their life turns up in melancholy continuously because of what it could not be or pass away loved ones recollections. These reasons lead young people to be piercing-jewelry sympathizers. Piercing is an ancient practice that is becoming massive in young people fashion. There are many piercing followers and non-followers, and each defend their point of view.

\section{KEYWORDS:}

Piercings, aperture, fashion, accessories, decoration, perforation adornment, art, youth, culture 


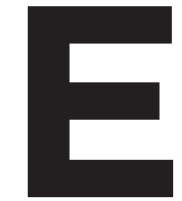

stas perforaciones son una forma de decorar la figura humana, de acuerdo a los criterios individuales de lo que pueda llamarse belleza. En el florecimiento del cristianismo, el body piercing (perforación corporal) era una forma de demostrar la debilidad de la carne y la sublimación del espíritu. En algunas culturas, solo son una forma de idiosincrasia primitiva y salvaje; para otras son modificación corporal y reflejan valores culturales, religiosos y espirituales. Desde hace algunos años, se ha tomado como una moda, de preferencia en los jóvenes y adolescentes.

No obstante su perspectiva en la moda de los últimos años, según los antecedentes históricos, esta práctica fue utilizada por antiguas civilizaciones y retomada en occidente por el movimiento hippie de los 70, en los 80 la cultura Punk, y en los 90, la New Age y su necesidad de sexo más placentero.

El piercing no es una invención de este siglo. Según expertos, esta práctica se emplea desde hace unos 60.000 años, tanto que fue registrado un ejemplo de destacado interés en Oriente medio, refiriéndose al piercing de la nariz, hace 4.000 años y además se menciona en la Biblia, en el libro de Génesis 24:22. Abraham pidió a su antiguo criado que encontrara una esposa para su hijo Isaac, el siervo encontró a Rebeca, "En cuanto los camellos acabaron de beber, tomo el hombre un anillo de oro de medio siclo de peso, que coloco en la nariz de la joven, y un par de brazaletes de diez siclos de oro en sus brazos"

A partir de esta referencia, en el antiguo Egipto, era usado solo por el Faraón, un pendiente en el ombligo que significaba formar parte de la realeza. Los soldados romanos y los gladiadores demostraban su fuerza viril con anillos en los pezones. En los templos mayas y aztecas los sacerdotes se colocaban un piercing en la lengua como signo de comunicación con los dioses, los esquimales colocaban un piercing en el labio inferior de las niñas recién nacidas como parte de un ritual de purificación y en los varones adolescentes como ritual de tránsito hacia la pubertad. Los materiales empleados podían ser piedras, hueso o marfil. En Norteamérica esta práctica era parte de la tradición de la cultura Sioux. Sin embargo fueron cayendo en desuso con las influencias del cristianismo europeo y americano. Actualmente algunas culturas de Asia, África y América continúan con el uso de dispositivos en los labios, orejas y nariz a manera de diferenciarse socialmente o simple decoración de su cuerpo. Entre estas etnias se distinguen los diferentes grupos entre ellos mismos, utilizando collares y otros adornos, identificando de esta manera los cazadores, los guerreros, la mujer del jefe de la tribu. Los piercing bucales son utilizados en algunos pueblos del Amazonas, del Sudan, Etiopia, chinos e hindúes con un significado religioso, sexual, familiar o marital. En la antigüedad, este tipo de accesorios solo eran utilizados por las mujeres, pero, desde hace siglos, esto cambió volviéndose una práctica también de hombres.

La práctica actual del piercing corresponde a una nueva forma de comportamiento social que involucra a los jóvenes y adolescentes de todas las latitudes, que se encuentran en la búsqueda de identidad, por lo que inician la construcción de una autoimagen que se adapte a sus necesidades sociales, psicológicas y biológicas.

Actualmente, el piercing se ha ido introduciendo en Colombia hasta convertirse en una forma de identidad adoptada por la población juvenil, para otros es una tendencia de moda que hace su incursión en todas las esferas sociales, sin distingos de sexo, raza, nivel de escolaridad, o condición social, haciéndose popular entre adolescentes.

Según las estadísticas, se estima que un $8 \%$ de los jóvenes mayores de 14 años lleva un piercing en alguna parte de su cuerpo, que se colocan de acuerdo a sus gustos, necesidades, su identificación con algún grupo o sencillamente para decorar su cuerpo o llamar la atención.

En la actualidad, existen millones de diseños de estas famosas piezas decorativas corporales, variando en texturas, formas, colores, tamaños, figuras, todo de acuerdo alas necesidades o pretensiones que el cliente asuma.

\section{DIFERENTES FORMAS DE PERFORACION}

Entre los piercings más solicitados y los lugares del cuerpo mas apetecidos para usarlos, se pueden mencionar:

Aro en el Labio: Es un aro que pasa por la parte inferior 0 superior del labio. Su ubicación puede variar, generalmente lo vemos entre los extremos del labio pero hay quienes los prefieren en el labio.

Labret: Se refiere a una sola perforación en el labio inferior y generalmente se realiza en el medio del labio. Para éste Piercing hay diferentes tipos, en punta, puntiagudos, de colores y con formas.

Labret Vertical: Pasa por el centro del labio inferior y por afuera. La barra tiene una ligera curva y es visible tanto por debajo del labio inferior como entre el labio inferior.

Piercing Horizontal: Se trata de una barra horizontal que va a través de la parte interior del labio y en la parte de afuera del labio muestra dos bolitas.

Picaduras de Ángel: Consiste en dos perforaciones del labio superior y del labio inferior y pasa la barra entre las perforaciones. Por lo general es normal ver dos a la vez, pero puede utilizarse uno.

Monroe: Es uno de los más populares y sensuales. Quedan muy bien y se sitúa en la parte superior del labio. Simula el sensual lunar de Marilyn Monroe y de ahí su nombre.

Lengua: Tiene función de estimulación sexual. Es de las más arriesgadas, se puede perder el sentido del gusto si no se hace bien. 
Oreja: Se usan con frecuencia joyas tipo banana que permiten que se recupere muy rápido. Se puede hacer por la parte de adentro o por afuera, como se prefiera y requiere alguien que tenga experiencia porque es de los más complicados entre los Piercings en las orejas.

Piercing en el Hélix: Está ubicado en la parte alta de la oreja, en el borde del cartílago. Casi siempre es pequeño, de diámetro corto y con una joya en forma de aro.

Piercing en el lóbulo: El más común de todos, donde las mujeres desde pequeñas tenemos zarcillos o aros de expansión con frecuencia. Sanan rápido, en unas 4 semanas. Daith: Se coloca en el cartílago de la oreja, arriba de la entrada al oído .

Rook: Una o mas perforaciones en la parte de arriba y dentro de la oreja.

Clítoris: Se puede atravesar totalmente (Clit), o parcialmente (Hood) perforando la fina piel que recubre la parte superior del clítoris puede ser horizontal o vertical: Cicatriza en un periodo relativamente corto y causa una excitación directa al clítoris durante la relación sexual.

Labios mayor y menor: Se suelen colocar por pares y normalmente suelen ser aros. Uno a cada lado. El más solicitado es el del labio inferior por su facilidad a la hora de realizar las curas. Se dice que antiguamente se perforaban los 2 labios y se ponía un candado para que las mujeres no tuvieran relaciones sexuales.

Prince Albert: Es uno de los trabajos más requeridos en el que se perfora la uretra en la base del glande y luego se introduce un anillo en el orificio realizado. Tiene la peculiaridad de curarse pronto, embellece e incrementa la satisfacción sexual. El nombre proviene del príncipe Alberto de Inglaterra, que lo puso de moda para recoger el pene evitando que se le notara cuando llevaba mallas y que la reina no se molestara. Dicen que estimula hasta cuatro veces más el orgasmo masculino.

Frenum: Perforación en la piel de la base del glande, el anillo rodea la cabeza del pene. Es una perforación muy simple pero igual de estimulante a la hora de mantener relaciones sexuales.

Apadravya: Es muy flexible. Se menciona en el kamasutra como un estimulador de la vagina. El proceso de curación es largo y delicado. Atraviesa la punta del pene en sentido vertical sobresaliendo la extremidad inferior de la base del pene.

Ampallang: Utilizado por las tribus de Borneo. Atraviesa horizontalmente la punta del pene, pudiendo o no pasar por el canal de la uretra. Para cicatrizar perfectamente deben pasar 6 meses.

Guigue: Es un Piercing horizontal situado en la tira de piel comprendida entre el escroto y el ano, en el referente del músculo erector, estimulándolo. Es muy difícil de realizar y muy molesto si se permanece sentado mucho tiempo.

Dydoes: Son 2 barritas de acero con 2 bolitas en los ex- tremos situadas en el borde del glande, permite recuperar sensaciones perdidas con la circuncisión.

Hafada: Orificio relativamente superficial situado al lado del escroto, entre el testículo y la raíz del pene, no es doloroso y es rápido.

Foreskin: Se practica en el prepucio y requiere un periodo de 2 o 3 meses para cicatrizar.

Pezón: Los romanos se los perforaban como símbolo de virilidad. En la época victoriana algunas damas ya destacaban sus pezones con esta perforación. La cicatrización es delicada y se pueden perforar de varias maneras, proporcionando un importante estimulo de placer y sensibilidad. Mejilla: Muy corriente, también, entre los punks de los años 70. Es una perforación provocadora pero sin duda es un piercing sencillo de hacer y de fácil curación.

Mano: Se realiza en el tejido ubicado entre los dedos.

Navel: Esta perforación de ombligo es uno de los piercingmás solicitados.

Nariz: Se pueden utilizar argollas o broqueles.

Ceja: Se realiza en esa zona del cuerpo y se recomienda utilizar argollas.

Septum: Se realiza en medio de los orificios de la nariz, abajo del tabique nasal.

Bridge Horizontal: Se perfora la piel del puente de la nariz a la altura de los ojos.

Surface: Múltiples y variadas perforaciones superficiales. Su cicatrización depende de la zona donde se realice.

\section{RIESGOS}

Son muchos los riesgos que puede ocasionar este tipo de perforación, se mencionan las más comunes:

- Infecciones locales, pueden surgir por la exposición de la herida a microorganismos, como hepatitis $C$, al igual que la sífilis, tétanos y SIDA, a falta de desinfección adecuada, no uso del antiséptico apropiado, no seguir el proceso de cuidados para la perforación y reutilizar objetos sin esterilización se convierten en alto riesgo. Aun siguiendo estos cuidados, es posible contraer infecciones, que pueden llegar a ser graves. En caso de padecer de enfermedades crónicas o tomar medicamentos que disminuyan la inmunidad, son más frecuentes: Staphylococus aureus, Streptococus del grupo A y Pseudomona; entre los virus: herpes virus y papiloma virus.

- En las zonas labiales puede producir algún desgarro en la encía que puede llevar a la de hueso periodontal, con daño permanente en incisivos inferiores y hasta llegar a la pérdida dental definitiva. A través de un estudio realizado por la Universidad Rey Juan Carlos de Madrid en España, se afirma que el $72 \%$ de las personas que poseen Piercings en alguna parte de la boca, sufren algún problema posterior a la colocación del adorno, alta cifra que evidencia los 
resultados de esta práctica. Aun así, tomando precauciones siempre hay riesgos. El cáncer de hígado o hepatocarcinoma derivado por virus de Hepatitis C se mantiene como una infección silenciosa y sin prácticamente síntomas hasta por 20 años posteriormente a la infección del virus.

- Reacciones alérgicas a los materiales utilizados Si se produce una reacción alérgica lo mejor es retirar el objeto. Dependiendo de la zona, de su importancia, y de su permanencia, en el tiempo se deberá consultar a un médico. Si la reacción alérgica se produce en la lengua, o mucosas bucales, se deberá acudir de inmediato a un centro de urgencias.

- Hemorragias originadas por la perforación de un vaso importante. En órganos de circulación abundante, como el pene 0 la lengua, puede presentar sangrado importante. - Alteraciones en la cicatrización. Cuando se hace una herida en la piel, se activan los factores de coagulación y cicatrización, estos últimos factores pueden, alterarse por diferentes causas y producir un engrosamiento de la cicatriz, lo que se conoce como queloides.

\section{Otros riesgos}

Perforación de un nervio o de un vaso sanguíneo Desgarros por traumatismos de la joya insertada.

Cáncer de lengua al trozar el aporte sanguíneo de los principales vasos y necrosis de la zona con daño irreparable. Edema de glotis, el cual se produce una inflamación de la lengua, la glotis, los tejidos de la boca (oro faringe) y como consecuencia, asfixia., que puede ser por varias causas.

Rechazo del cuerpo: cada cuerpo actúa ante una joya de distintas maneras, puede ser que el cuerpo lo acepte y se cicatrice correctamente o lo rechace y luego de unos meses no puedas llevarlo más

En el caso de los perforados orales, pueden provocar perdidas de piezas dentales si no se tienen las adecuadas precauciones .

En la mayoría de los establecimientos que realizan el piercing, el cliente no recibe la información necesaria para saber si puede o no decorar su cuerpo con estas técnicas no exentas de riesgos y para evitar los problemas que puedan surgir. Es decir, hace falta manifestar a los clientes las condiciones de riesgo que puedan sobrevenir por el uso de estas técnicas. De igual manera, debe existir un compromiso de ambas partes que establezca los pro y los contra que pueda implicar este tipo de prácticas y de esta forma crear conciencia que sirva de indicador a las personas que se someten a estas acciones.

Refiriéndose a los piercing y tatuajes, recomienda que "lo primero a decir sobre este tema es que desde el punto de vista médico y sanitario, se trata de una práctica desaconsejable: en ambos casos se producen heridas en la piel o en ciertas partes del cuerpo y tanto en Piercings como en tatuajes existe el riesgo de reacciones alérgicas y de contraer - por contagio vía utensilios no debidamente esterilizados- enfermedades graves como el SIDA o la hepatitis".

\section{LA DECORACION, COEXISTE CON EL DOLOR}

Desde tiempos remotos, el ser humano ha sido impulsado por la religión, el arte, la cultura, supersticiones, costumbres, estética o la moda, a diferentes manifestaciones y expresiones, y como en este caso, colocar insignias en su cuerpo. También es muy cierto que cada quien es libre de hacer con su cuerpo lo que quiera, mientras tenga las posibilidades de hacerlo, siendo capaz de desafiar las limitaciones familiares o sociales que le rodean. La práctica de la decoración corporal ya sea con tatuajes o piercings, siguen siendo quizás las tendencias mas usuales entre este tipo de publico, debido a que a través de un diseño propio o existente pueden mandarse a dibujar permanentemente algún tipo de simbolismo en la piel, o agujerarse en cualquier parte del cuerpo con pendientes, zarcillos, aros, colmillos, o con cualquier otro tipo de elemento que para muchos se torna de orgullo decorativo corporal.

\section{¿Pero si esta práctica es tan dolorosa por qué hacerla?}

En algunos de los casos, es realmente inevitable hacerlo, como en el caso de aquellas tribus en las que significa el cambio de la niñez a la edad madura de las mujeres, con lo que se les considera fecundas y aptas para la actividad sexual.

En Occidente, se ha tornado toda una experiencia emocional y de rebeldía para la juventud que ha crecido influenciada por géneros como el rock, heavy metal, el punk, y por aquellas relaciones entre los adultos de la época de los $60^{\prime}$ s con sus hijos, quienes de alguna manera buscaban una propia forma de vida con la que se sintieran identificados. Algunos, por el excentricismo del momento y otros, quizás, dejándose envolver por la enajenación que les producía la marihuana.

Algunos jóvenes encuentran en esta práctica una salida 0 escape hacia una vida más controlada dentro de su propio descontrol, en el que por fin logran sentirse aceptados dentro de una pequeña cultura que ha ido creciendo excesivamente y que ahora es más popular por todos sus aspectos en todo el mundo. Si bien es cierto que un número de jóvenes adoptan este comportamiento debido a factores sociales, familiares o para ser aceptados por su grupo, pero que a la vez son rechazados por los que no están de acuerdo con esta moda, argumentando que el piercing ocasiona daños físicos, que se pueden contraer enfermedades o que no concuerda con las bases morales recibidas en el hogar.

Muchos jóvenes ven los piercing como algo atractivo, otro tanto por estar a la moda, pero a partir del principio 
ARTE \& DISEÑO, ISSN: 1692-8555, Vol. 10 Núm. 1, Enero - Junio de 2012 NANCY ROSARIO BRIEVA HURTADO

de conservación, cada persona debe emplear aquello que lo haga sentir cómodo sin dañar su cuerpo, ni su mente. Pero nuestros jóvenes recurren a estas técnicas para "diferenciarse" de sus congéneres y para obtener reconocimiento y respeto frente a los demás.

Quizás, para otros puede significar el castigo que inconscientemente se imponen por conductas o comportamientos desadaptados o rebeldes, por culpas que llevan a cuestas o por vacíos "existenciales" que no pueden llenar, situaciones sin aceptar, puertas que han quedado a medio cerrar, páginas de sus vidas que no han pasado, círculos que no se han cerrado. Todo esto si se agrega la formación sociocultural a las que han sido sometidos durante muchos años, con los hogares disfuncionales, padres ausentes, distantes imbuidos por el encanto de la tecnología y con el único medio de comunicarse con sus hijos a través de una maquina.

Muchas veces se piensa que el dolor es castigo, fastidio, repulsión, o solo se debe dejar a los masoquistas (personas que les gustan las prácticas físicas donde el principal ingrediente es el dolor), 0 a aquellos quienes deban pagar por quebrantar determinante la ley. Pero, lejos de ello, no se alcanza a imaginar que en muchísimos casos el dolor es más común y apetecido de lo que se suele pensar, ya que para algunas personas esto se traduce en placer, o también transformarse en un modo fuerte de darle un significado a las creencias y vivencias de la vida en la que, como frase célebre, reinaría la que dice "si no duele no sirve". De esta manera, cientos de personas en el mundo por medio de sus perforaciones o decoraciones corporales como bien se les llama, representan una experiencia personal en la que como ícono de inspiración recurren a personas de su familia o seres queridos que en algún momento marcaron en gran parte sus vidas.

Los piercing en realidad, constituyen un acto de agresión contra el cuerpo que requiere de responsabilidad y cuidado para no lamentar después las consecuencias.

Perforarse el cuerpo puede llegar a tener diferentes significados, dependiendo el fin de quien lo practica. Cuando se quiere expresar, sin ser tenido en cuenta, el cuerpo es una forma más de expresión, pero debe ser tratado con respeto para que no se vuelva banal y sin sentido.

En definitiva, cualquiera que sea el motivo para practicar las perforaciones depende de la libertad de elección de cada uno y de su decisión personal, pero lo que resulta grave es hacerlo por parecerse a otro, por la presión de un grupo o subcultura, o por seguir al cantante favorito, a los actores de series de televisión, modelos o deportistas del momento, sin estar plenamente conscientes de por qué lo hacen, cuáles son los riesgos y consecuencias de esta práctica. $\mathrm{Si}$ lo hacen por curiosidad o solo por estar en la onda de hoy.

\section{REFERENCIAS BIBLIOGRÁFICAS}

DANNY, Yerna; MARTÍNEZ Karen. Perforaciones corporales: Ritos, tradición, moda y dolor., México, D.F.: Wakantanka, [2000]

http://www.cuerpoyarte.com/2011-02-03/24715/tipos-

de-piercing-en-el-labio

http://www.piercing-abundancia.es/categorie.

aspx? corps $=6$

http://www.lacapital.com.ar/informacion-

gral/-20080923-0019.html

http://www.monografias.com/trabajos69/uso-piercing

www.tattoovigo.com/piercing

http://piercingsytatuajes.wordpress.com/2009/11/25/7

http://es.wikipedia.org/wiki/Piercing

revista.consumer.es/web/es/20040301/pdf/tema-de-

portada.pdf 